\title{
IV-ICAM'95 Weaves México's Interests with Advances in Materials Research
}

The Fourth International Meeting on Advanced Materials (ICAM-IV) was held in Cancún, México from August 27 to September 1, 1995. The meeting was organized by the Academia Mexicana de Ciencia de Materiales (AMCM), with assistance from the Materials Research Society (MRS) and sponsorship of the International Union of Materials Research Societies (IUMRS) and The Minerals, Metals, and Materials Society (TMS). Over 1,000 people attended 32 symposia on various topics of interest to the international materials community. Many of the symposia were of particular interest to México, the host country.

Cancún, located on México's Yucatán peninsula, provided the backdrop for one of the newest areas of materials science. Near the end of the Cretaceous period ( 50 million years ago) a huge meteorite known as the Chicxulub impactor smashed into the Yucatán peninsula, throwing an estimated 100-1,000 billion tons of $\mathrm{CO}_{2}, \mathrm{SO}_{2}-\mathrm{SO}_{3}$, and $\mathrm{H}_{2} \mathrm{O}$ into the

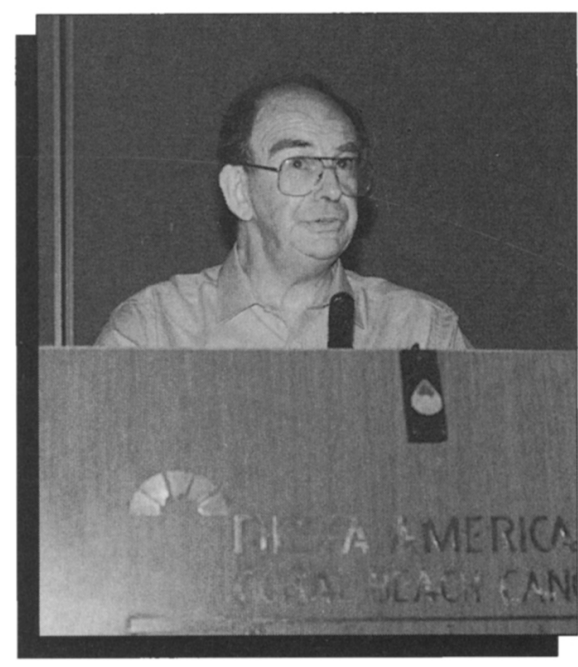

J.M. Thomas of the University of Cambridge gave a plenary talk on "Techniques and Adventure in SolidState Materials" at IV-ICAM'95 in Cancún, México. air. Solid ejecta has been found in many places, including Belize in Central America and New Mexico in the United States, causing secondary impact craters. A symposium on Planetary Impact Events: Materials Response to Dynamic High Pressure drew an international group of scientists who discussed the evidence for the global impact of this event which is often associated with the disappearance of the dinosaurs. The symposium was highly interdisciplinary, involving materials scientists, geologists, astrophysicists, chemists, and physicists. Topics included remote sensing of impact zones and impact modeling, including use of recent data from 1995 Jupiter impact events to simulate the Chicxulub impactor.

A symposium on Preservation of Ancient Monuments heavily represented the materials science of preservation of México's many monuments from ancient to modern times. This topic was an outgrowth of MRS's symposium Materials Science in Art

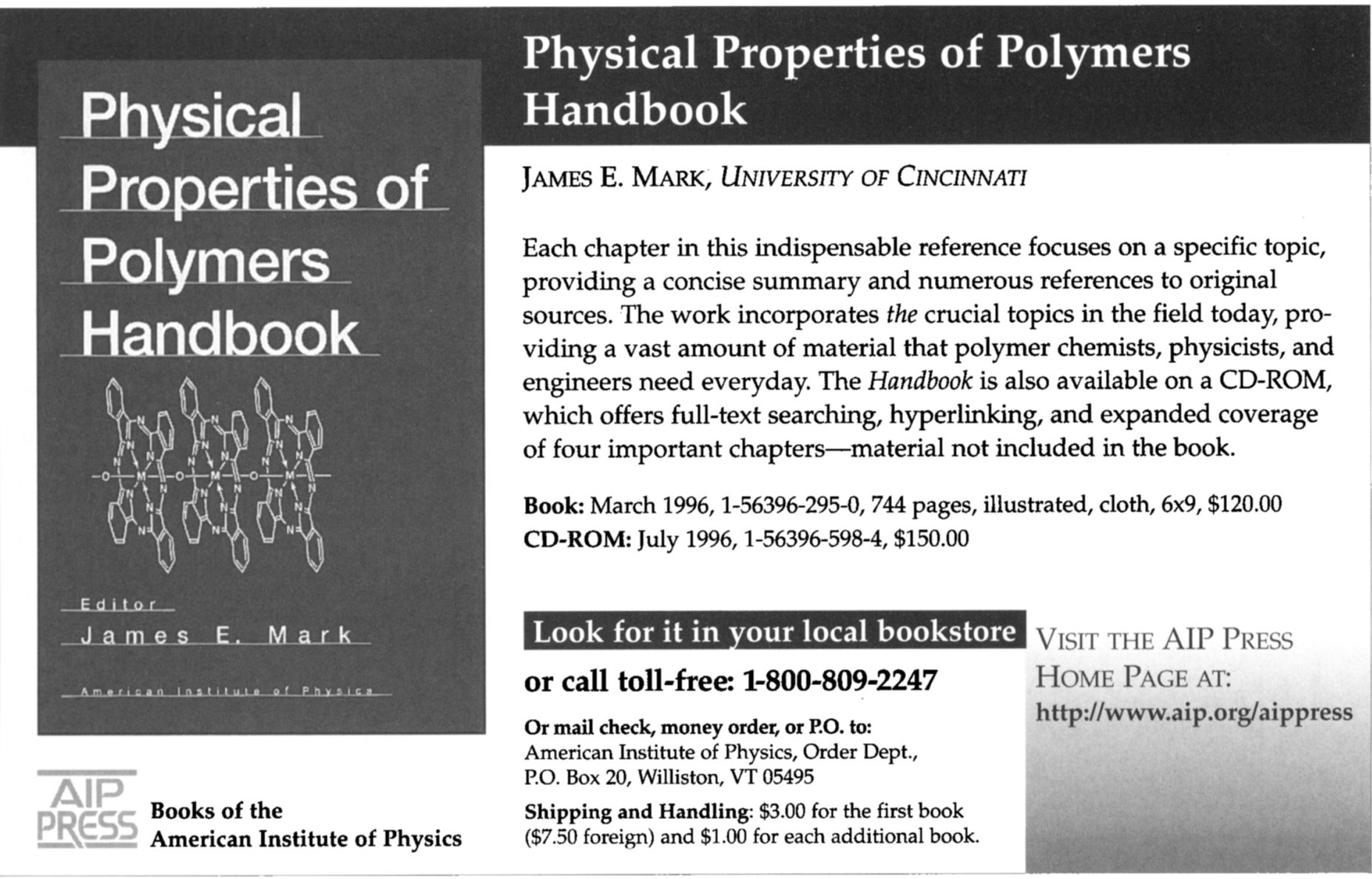

Circle No. 36 on Reader Service Card.

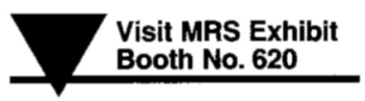


and Archaeology, which originated at the 1988 Spring Meeting in Reno, Nevada. That symposium temporarily moved to Cancún in May of 1994, leading to México's continuing interest in this area. Evaluation and preservation of ancient stones were a central theme, presenting "state-of-the-art" techniques. The philosophical basis for restoration as a part of historical heritage was outlined by Carlos Chafon Olmos of the Falcultad de Arquitectura, UNAM, as a fitting introduction to the technical sessions which followed.

Symposia on Advanced Cement Materials, Glass Materials Science and Engineering, and Advanced Technologies and Industrial Ecology in the Steel Industry focused on areas of material science of great importance to México since the cement and glass industries are among México's largest. Materials Issues in Corrosion dealt with México's major concern about corrosion problems due to the tropical and marine climates of major industrial areas. For example, the petroleum industry in the Gulf of Campéche suffers from an extremely corrosive environ- ment. Microbial-influenced corrosion and biofilm formation were extensively discussed. México produces a large variety of natural fibers. The incorporation of these fibers into composite materials was the subject of a symposium on Nontraditional Use of Fibers.

Environmental issues were also a major focus of ICAM-IV given the concerns in México and at the U.S./Mexican border. Two symposia, Environmental Catalysis and Environmental Materials: Issues \& Developments, provided lively discussion and intense debate. John Armor of Air Products lectured on "Catalysis: One Approach to Improving Our Environment," covering various aspects of catalytic. control of emissions from automobiles and stationary power plants. Victor Castaño of UNAM presented "Challenges and Opportunities in Recycling of Polymeric Waste," in which he covered the general theoretical framework and chemistry of the role of recycling.

Among traditional materials topics were Nanostructured Materials, Advanced Magnetic Materials, and Expanded

\section{Announcement}

\section{Sixth Conference on Computational Research on Materials} May 8, 9, and 10, 1996

\section{Lakeview Resort and Conference Center Morgantown, WV} Abstract Deadline - April 8, 1996

Join leading material researchers from universities, industry, and national laboratories in assessing the aims and latest developments in computational materials research:

- industrial applications of computational materials modeling

- atomistic and continuum modeling for the design of both structural and electronic materials systems

- the role of highly parallel computing for specific problems

- linking experimental verification to atomistic and continuum modeling

- the national materials research agenda and materials modeling

Program Chairs:

B.R.Cooper-Physics,WVU; K.M.Chang-Mechanical Engineering, WVU; and, S.T.Pantelides-Physics, Vanderbilt U.

For more information, contact:

Martha Spenger, WV EPSCoR, West Virginia University, PO Box 6845, Morgantown, WV 26506-6845, Phone (304) 293-8274, FAX (304) 293-8155
Horizons of Fullerene Science and Technology. Eiji Osawa of Toyohashi University of Technology provided evidence that fullerenes are a component of Chinese ink sticks or Sumi. These inks have been prepared for centuries through the slow burning of pine wood and other natural oils producing small amounts of fullerenes which are thought to enhance the ink gloss.

A first-time forum at ICAM-IV was "Economics and Policy in Materials Research and Processing." This forum introduced economic factors that are driving materials research and production in a dynamically changing world. Professor of economics Patrick Cohendet of Universite Louis Pasteur in Strasbourg introduced the concept of "Variety Versus Standardization in Material Processing and Uses." He emphasized that "overchoice" of materials available, for example in the automotive industry, was leading to a growing complexity in the management of production processes. Examples of cooperative research as government policy for materials in the European Union, an international trading block, were also discussed.

Finally, capping the week was a symposium on Materials Science of Musical Instruments of the Americas. This symposium, which first appeared as Materials Science of Musical Instruments at the Spring 1994 MRS Meeting, captured the development of musical instruments in the Americas from both indigenous peoples and from the European colonists. A large array of instruments were discussed and demonstrated, including pre-Colombian instruments, central American marimbas, drums of the southern plains Indians, hammered dulcimers, and the glass harmonica which Benjamin Franklin reportedly invented in 1761. Materials issues and the physics of many of the instruments were presented in detail. A highlight of this symposium was the demonstration of steel drum technology by Ellie Mannette and his collaborators at West Virginia University. A concert by this group clearly demonstrated how Mannette has developed the steel drum from a folk instrument into a new concert medium.

\footnotetext{
Russell R. CHIANELLI AND
} MiguEL JOSE YACAMAN
News about IUMRS conferences and other activities should be sent to: MRS Bulletin
Materials Research Society
9800 McKnight Road
Pittsburgh, PA 15237-6006
Fax 412-367-4373
E-mail Bulletin@mrs.org 


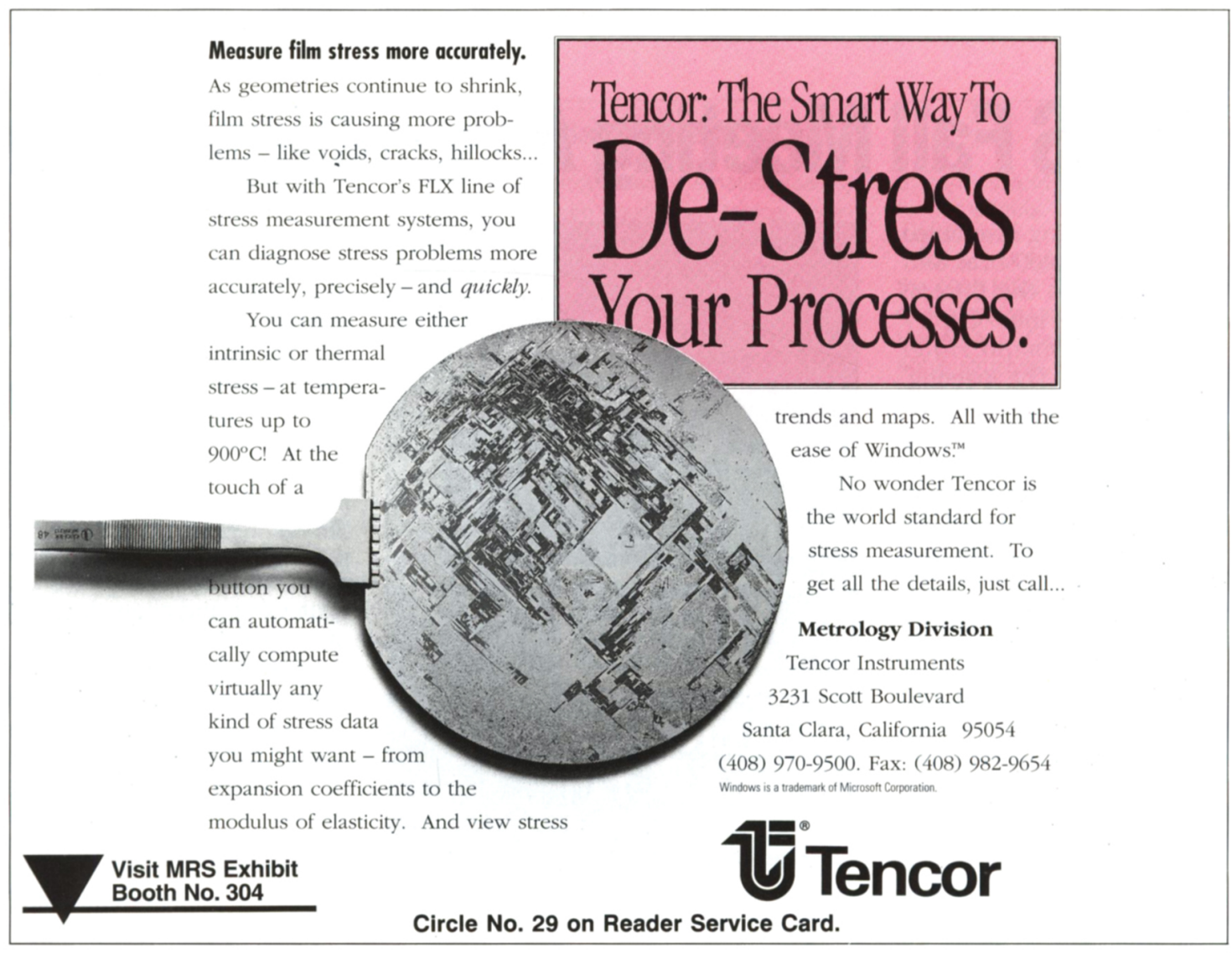

\section{MeV Ion Beam Systems and Components}

NEC Pelletron $®$ Accelerator Systems provide ion and electron beams for RBS, PIXE, AMS, $x$-ray imaging, NRA and hundreds of applications in the physical, chemical and biological sciences. NEC beamline components are ultra-high vacuum compatible. NEC acceleration tubes are metal/ceramic bonded, inorganic and fully bakeable.

- Beam Steerers

- Raster Scanners

- Slit Systems

- Faraday Cups

- All Metal Valves

- Electron and Ion Sources

- Light Link Systems

Systems and Components in 37 countries.

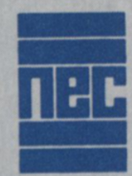

\section{National Electrostatics Corp.}

7540 Graber Road, Box 620310

Middleton, WI 53562-0310

Telephone: (608) 831-7600 • Fax: 608/256-4103
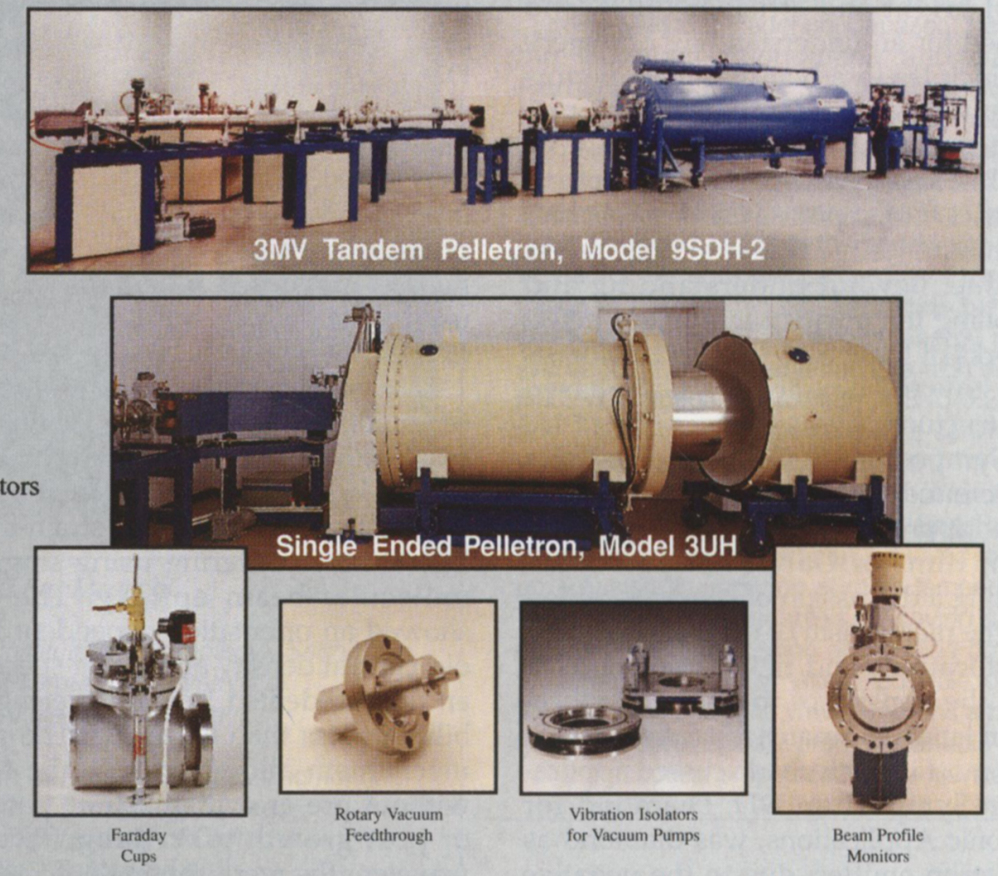

Visit MRS Exhibit Booth No. 307

Circle No. 20 on Reader Service Card. 